\title{
Influence of global warming on coastal infrastructural instability
}

\author{
K. Yasuhara $\cdot$ S. Murakami $\cdot$ N. Mimura $\cdot$ \\ H. Komine $\cdot$ J. Recio
}

Received: 27 February 2006/ Accepted: 27 September 2006/Published online: 8 December 2006

(C) Integrated Research System for Sustainability Science and Springer 2006

\begin{abstract}
The increasing infrastructure instability is an important issue in relation to the influences of global climate change in urban areas. A serious issue pertaining to this is the dual nature of damage triggered by events combined with climate change and natural hazards. For example, catastrophic damage could result from the combination of global warming with a great earthquake, which is a worst-case scenario. Although this worst-case scenario has rarely occurred and presents a low probability of occurrence, countermeasures must be prepared in advance based on an appropriate response and adaptation strategies. After an overview of possible infrastructural instabilities caused by global warming, methodologies are proposed placing emphasis on the increasing probability of infrastructural instability triggered by natural hazards resulting from groundwater-level (GWL) variations. These effects are expected to be particularly serious in coastal regions because of the influence of the rising sea level resulting from global warming. The influence of sea-level rises (SLR) will become apparent along with land subsidence
\end{abstract}

K. Yasuhara $(\bowtie) \cdot S$. Murakami $\cdot$ H. Komine

Department of Urban and Civil Engineering,

Ibaraki University, 4-12-1 Nakanarusawa,

Hitachi, Ibaraki 316-8511, Japan

e-mail: yasuhara@mx.ibaraki.ac.jp

\section{N. Mimura}

Center for Water Environment Studies,

Ibaraki University, 4-12-1 Nakanarusawa,

Hitachi, Ibaraki 316-8511, Japan

\section{J. Recio}

Leichtweiss-Institute for Hydrodynamics and Coastal Engineering, Technical University of Braunschweig, Braunschweig, Germany because groundwater abstraction will become severe in coastal regions. Additionally, the probability of earthquake liquefaction increases if GWL rises in accompaniment with SLR. Using case histories, we examined the possible occurrence of these natural hazards as a result of global warming. Finally, possible countermeasures and adaptation strategies for reducing and mitigating infrastructure damage accelerated by global warming are described for each case in specific regions. In particular, special attention should be paid to adaptation strategies in coastal lowlands, which particularly suffer from the effects of land subsidence.

Keywords Global climate change - Sea-level rise . Dual hazard · Groundwater level · Land subsidence . Liquefaction - Earthquake - Countermeasure . Adaptation

\section{Introduction}

The increasing infrastructure instability is an important issue in relation to the influences of global climate change in urban areas. A serious issue pertaining to this is the dual nature of damage triggered by events combined with climate change and natural hazard, as shown in Figs. 1 and 2. One example of a cataclysmic worst-case scenario would be a period of global warming punctuated by a large earthquake. Although such a scenario is unlikely to occur today or next month, we should prepare countermeasures in advance based on an appropriate response and adaptation strategies. After summarizing an overview of possible infrastructural instability caused by global warming, methodologies are proposed by particularly examining 
Fig. 1 An example of a dual hazard

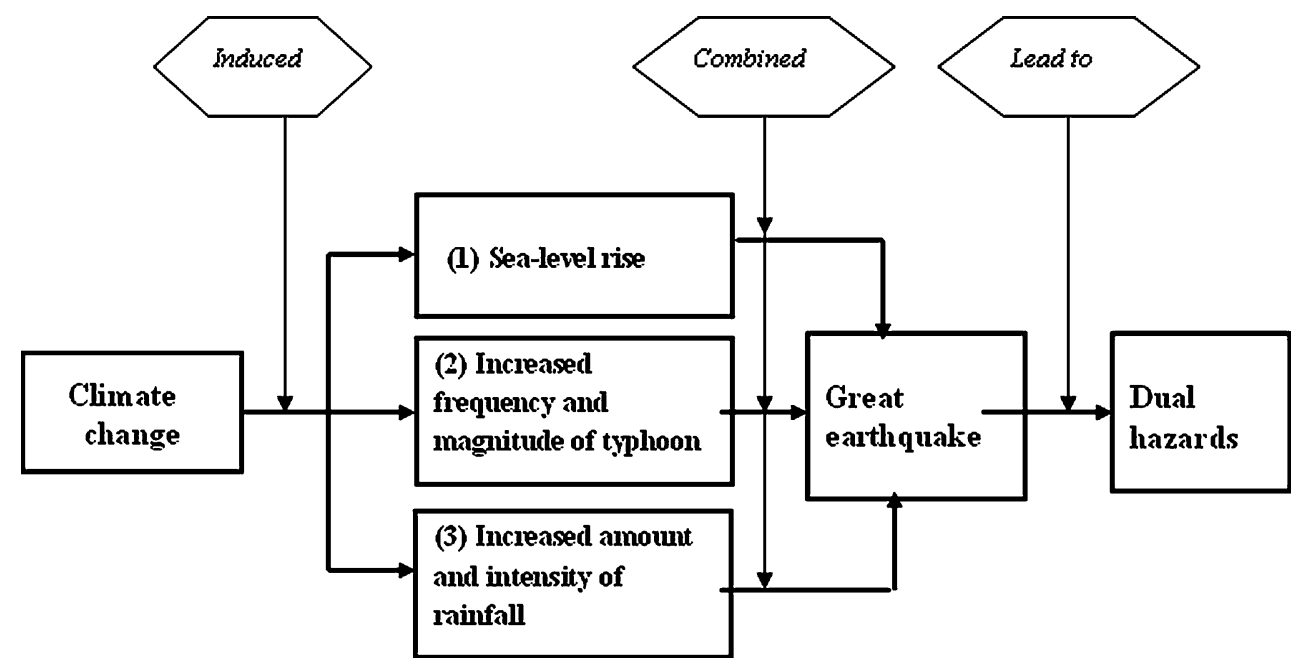

Fig. 2 Schematic diagram for combined disasters and their adaptation

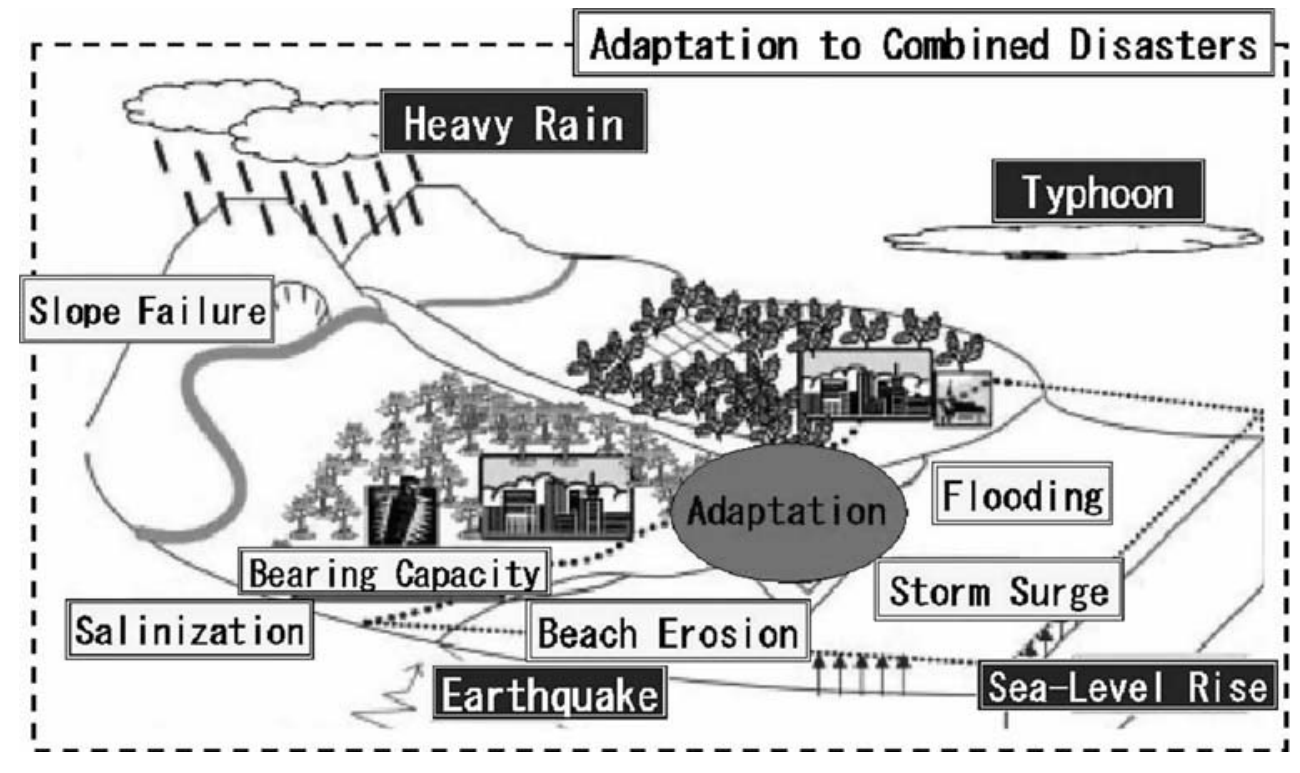

the increasingly possible infrastructural instability due to groundwater-level (GWL) variations combined with a disaster triggered by natural hazards. Such a scenario especially confronts coastal regions because such regions are influenced by a sea-level rise (SLR) attributable to global warming. The influence of SLR will become apparent along with land subsidence, because groundwater abstraction will become severe in coastal regions. Additionally, earthquake liquefaction can occur if the GWL rises concomitant with SLR. Using case histories, we examined the possible occurrence of these natural hazards as a result of global warming. We also propose possible countermeasures and adaptation strategies for mitigating damage for each case in specific regions. This report is intended to help administrations devise policies and strategies to mitigate damage caused by climate change.

\section{Influence of global warming on infrastructural instability}

From a geotechnical point of view, as depicted by the event tree in Fig. 3 (Yasuhara and Adachi 1994), the issues most relevant to the influence of global warming are: (1) SLR, (2) change in air circulation, and (3) increased ground-surface temperatures. Possible phenomena pertaining to geotechnical and geoenvironmental changes are summarized in Table 1. The effects of GWL variations are featured in this paper as a challenging issue from among those presented in Table 1.

Land subsidence takes place if the GWL becomes lower as a consequence of groundwater abstraction. In particular, if this occurs in or near coastal areas, this duplicates the influences of SLR, as illustrated in 
Fig. 3 Event tree for geotechnical issues triggered by global warming (Yasuhara and Adachi 1994)

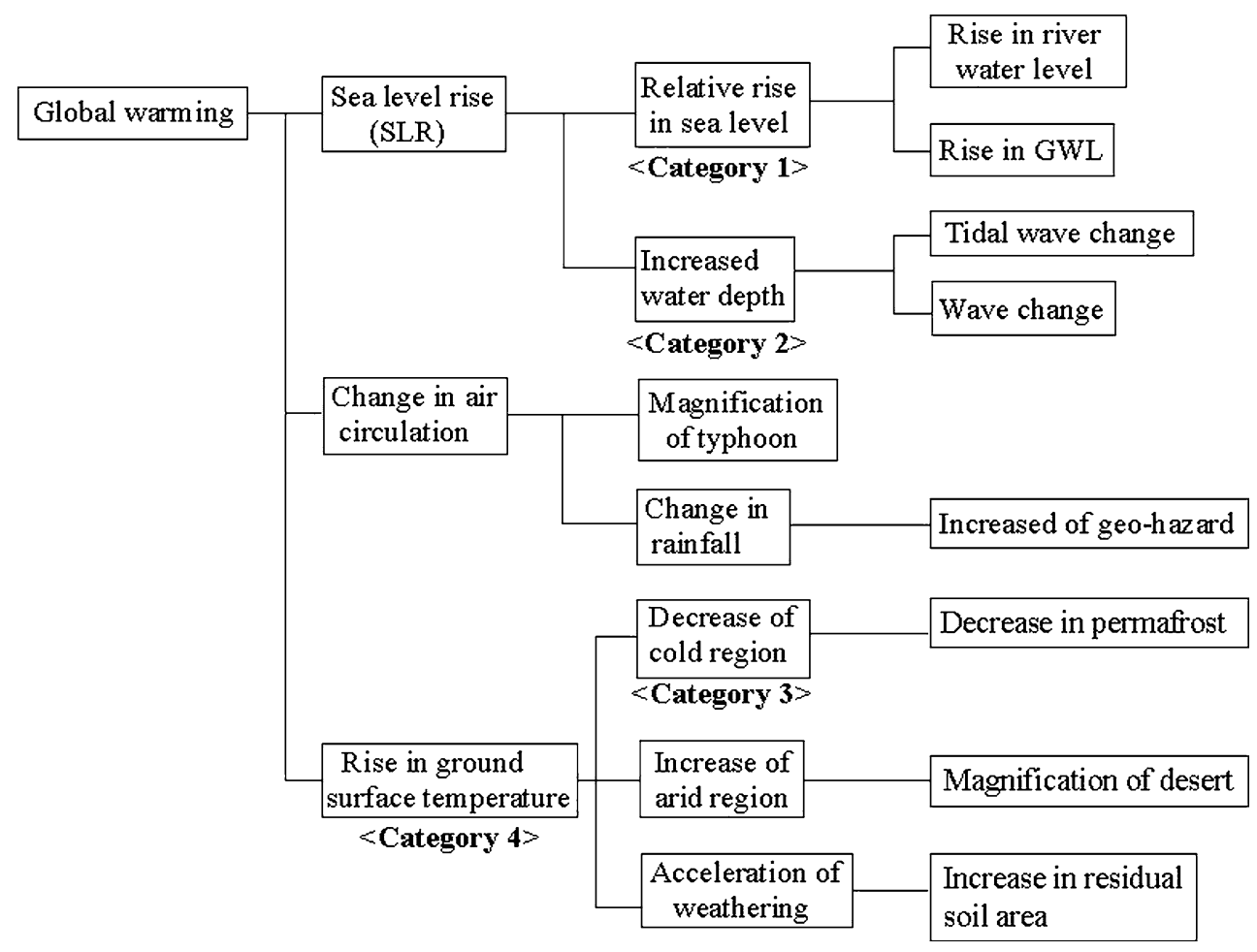

Table 1 Summarized geotechnical issues caused by global warming (Yasuhara and Adachi 1994)

\begin{tabular}{|c|c|c|}
\hline \multirow[t]{2}{*}{ Category } & \multicolumn{2}{|l|}{ Events } \\
\hline & Physical event & Possible concrete event \\
\hline \multicolumn{3}{|l|}{ (1) Sea-level rise (SLR) } \\
\hline Increase in groundwater level (GWL) & Decrease in effective stress & Decrease in bearing capacity \\
\hline \multirow[t]{4}{*}{ Increase in river-water level } & Swelling & Collapse of soil structure \\
\hline & Uplift force & Floating of structure \\
\hline & Seepage & Seepage failure \\
\hline & & Piping \\
\hline \multirow[t]{3}{*}{ (2) Increased water depth } & Change in tidal wave & Displacement and settlement of foundations \\
\hline & Wave-induced force & Damage of structures \\
\hline & & Increase of erosion \\
\hline \multirow[t]{2}{*}{ (3) Change in rainfall } & Prolongation of rainfall & Increase in landslide and slope failure \\
\hline & Increase in rainfall intensity & \\
\hline \multirow[t]{3}{*}{ (4) Rise in ground-surface temperature } & Thawing of frozen soil & Decrease in bearing capacity \\
\hline & Acceleration of weathering & Increase in disasters of residual soils \\
\hline & Magnification of desert & \\
\hline
\end{tabular}

Figs. 4 and 5, which induces more severe damage to infrastructure than occurs inland. Climate-change-induced severe rainfalls would increase flooding in lowlands, which would accelerate the effect of land subsidence.

On the other hand, SLR engenders a rise in GWL, which induces foundation instability by: (1) decreasing bearing capacity; (2) fostering settlement of the ground and foundations; and, in a worst-case scenario, (3) floating foundations and buildings. SLR occurs gradually over a long period, perhaps years. Therefore, this effect is not noticeable over a short period. However, as shown in Fig. 1, global warming is likely to induce higher rainfall because of more severe typhoons, and the subsequent intrusion of rainfall water into the ground would abruptly raise the GWL. Although it is expected that the SLR will increase a few millimeters per year in the following years, the GWL induced by SLR will be much higher because of the increased intensity and duration of rainfall, as shown in Fig. 6. Consequently, GWL rise could be much higher than the measured sea level. In fact, the foundations of 


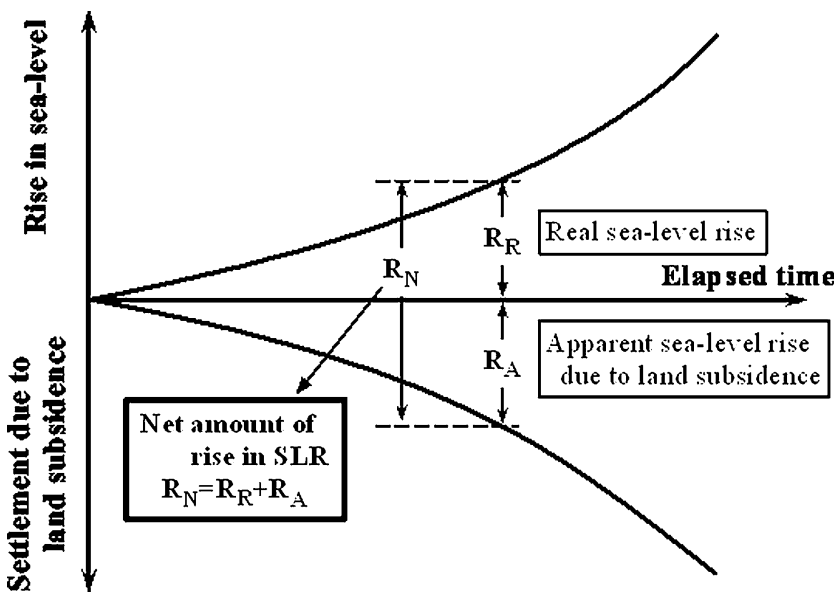

Fig. 4 Acceleration of seal-level rise (SLR) duplicated by groundwater level (GWL)

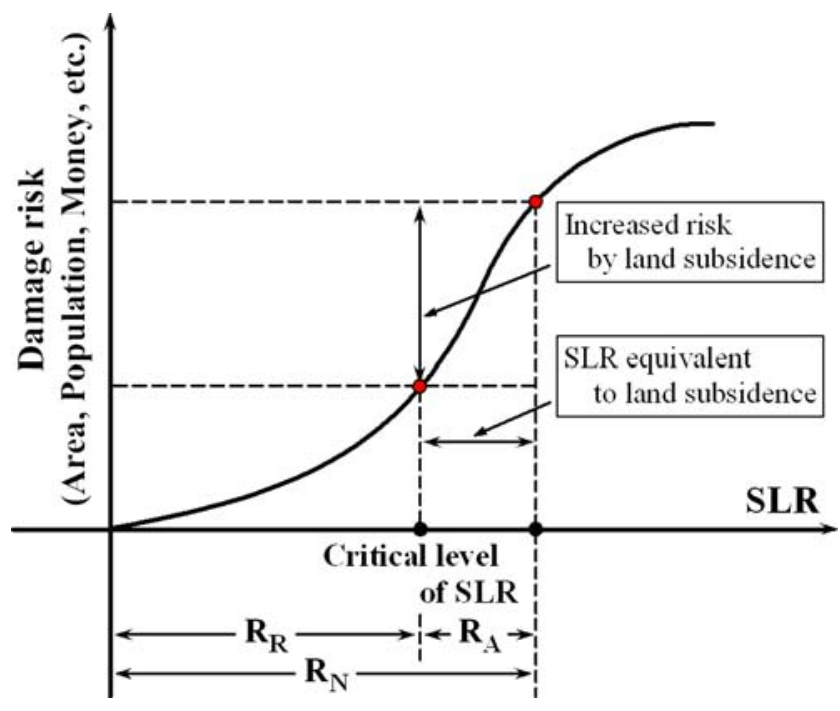

Fig. 5 Increased risk from land subsidence

some of the buildings in Ueno, Tokyo, and Kodaira Stations (Kusumi and Matano 2005) have become threatened by instability attributable to the excessive uplift force that exceeds the weight of the buildings themselves, particularly because of substructures that have no pile foundations. For that reason, the Eastern Japan Railway Agency decided to install anchors to avoid the floating of substructures and superstructures at those stations. In addition, GWL has recovered gradually in large cities after groundwater abstraction was regulated to reduce land subsidence. This recovery of GWL increases the risk of floating buildings. In summary, rising GWL is triggered not only by SLR, but also by heavy rainfall and termination of groundwater abstraction, as shown in Fig. 6.

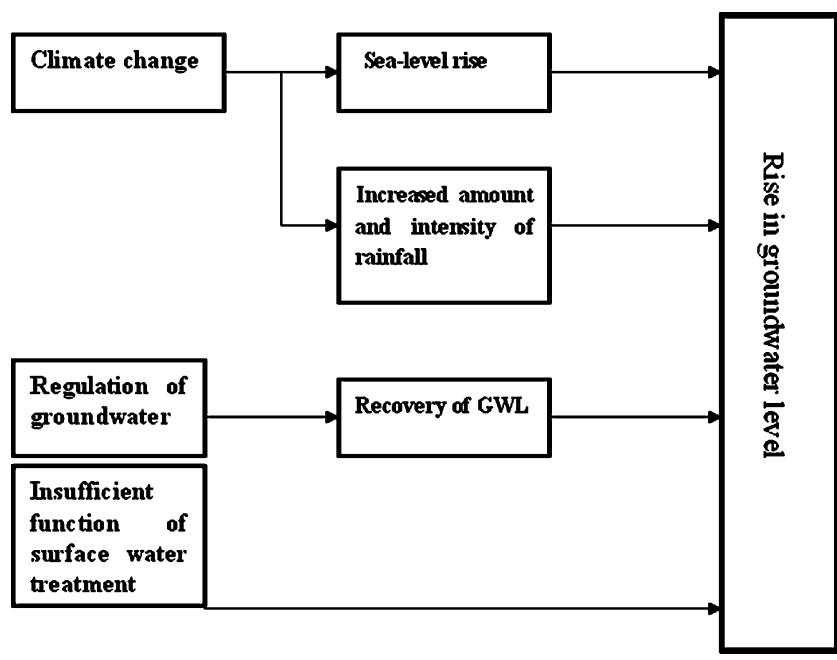

Fig. 6 Causes for rise in groundwater

An example of the recovery of GWL in Tokyo caused by termination of groundwater abstraction is shown in Fig. 7.

\section{Methodology for predicting infrastructural instability}

Infrastructural instability resulting from land subsidence

Predictive methodologies for land subsidence caused by groundwater abstraction are classifiable into two categories: one is prediction before groundwater abstraction; the other is prediction after land subsidence takes place, the so-called "observational prediction procedure." The latter procedure is based on settlement versus elapsed time records obtained at locations that have shown vertical displacement of the ground surface and for which local governments have observed variations in GWL over time. The observational procedure for prediction of land subsidence in the northern Kanto plain was proposed by Murakami et al. (2002). On the other hand, the former procedure has traditionally and commonly been adopted in the field of geotechnical engineering. This conventional procedure requires geological and geotechnical information obtained from site investigations, and laboratory testing of soil specimens taken from respective sites. However, numerous site investigation procedures, e.g., standard penetration test (SPT) and sampling, are necessary to carry out conventional settlement analyses, mainly using consolidation theory to show time-dependent variations of settlements for a wide objective region. However, this is time consuming and costly. For this reason, we have adopted the observational procedure for this study. It is given as 
Fig. 7 Example of rising confined groundwater level (GWL) in Tokyo

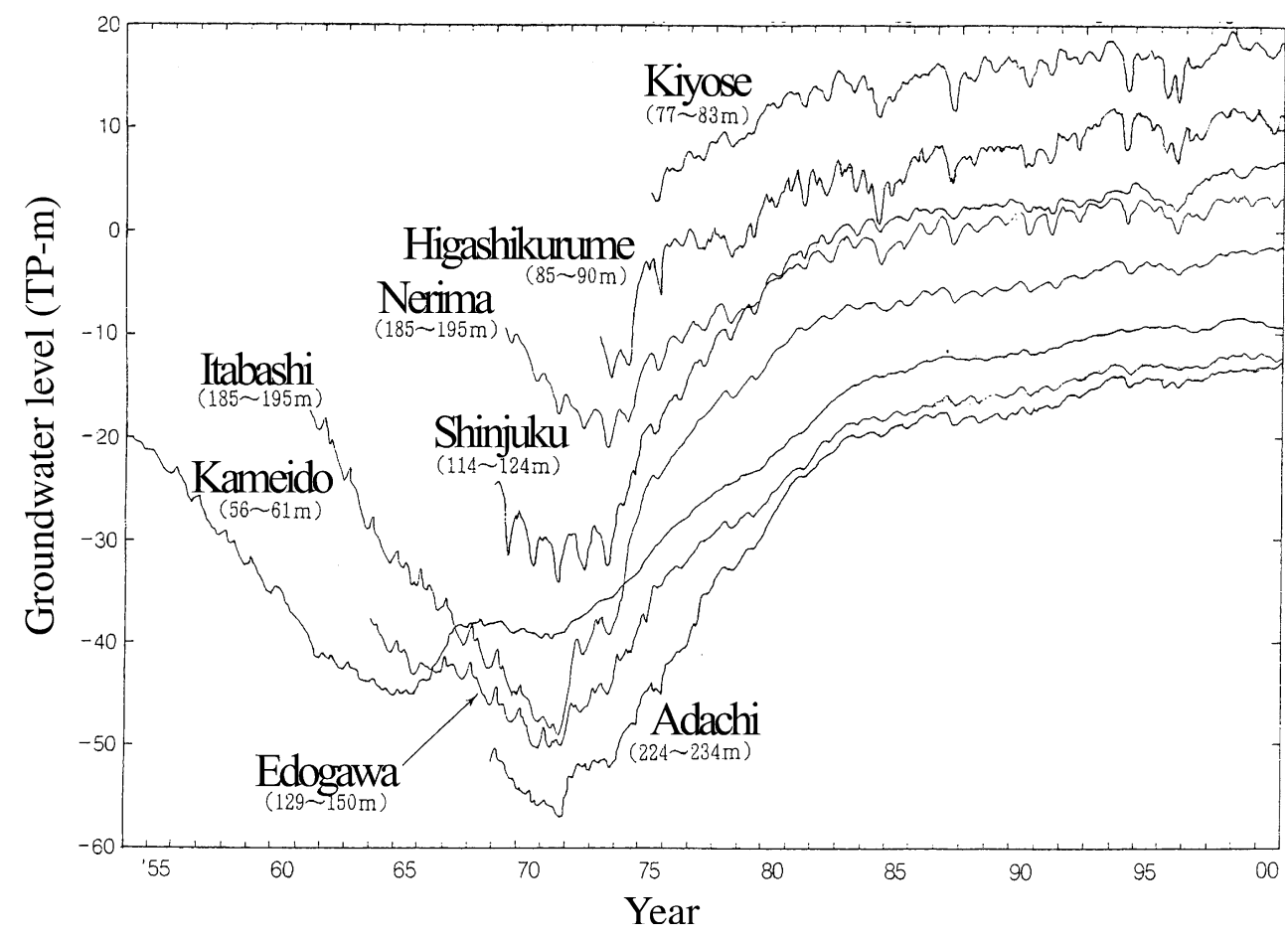

$S=S_{p 0}\left\{1-\exp \left(-C_{R} \cdot t\right)\right\}$

where the following are true.

$C_{R}=\frac{c_{v}}{4 \bar{H}^{2}}$

$S_{p 0}=S_{f} \frac{8}{\pi^{2}} \exp \left(-\frac{T_{\nu 0}}{4}\right)$

These parameters were determined from records of field settlement observations employing the following nonlinear least-squares method:

$F=\sum_{i=1}^{n}\left[\delta S_{i}-S_{p 0}\left\{1-\exp \left(-C_{R} \delta t_{i}\right)\right\}\right]^{2}$

$\frac{\partial F}{\partial C_{R}}=\sum_{i=1}^{n} 2\left(-\frac{\partial f_{i}(x)}{\partial C_{R}}\right)\left\{\delta S_{i}-f_{i}(x)\right\}=0$

$\frac{\partial F}{\partial S_{p 0}}=\sum_{i=1}^{n} 2\left(-\frac{\partial f_{i}(x)}{\partial S_{p 0}}\right)\left\{\delta S_{i}-f_{i}(x)\right\}=0$

Evaluation of rise in groundwater level caused by a rising sea level

Groundwater flow analyses based on the finite element method were performed to obtain the GWL for calculating the liquefaction potential. Solving the equation of analysis yields a two-dimensional (2D) model for unconfined groundwater flow in steady conditions:

$\frac{\partial}{\partial x}\left\{k\left(h-z_{0}\right) \frac{\partial h}{\partial x}\right\}+\frac{\partial}{\partial y}\left\{k\left(h-z_{0}\right) \frac{\partial h}{\partial y}\right\}=0$,

where $h$ is the GWL, $k$ is the coefficient of hydraulic conductivity of the permeable soil layer, $z_{0}$ is the depth of the nonpermeable surface, and $x, y$ are coordinates of the horizontal plain. Equation 6 is obtained from the continuum equation for groundwater flow in three dimensions assuming steady groundwater flow conditions. Inflow/outflow on both the ground surface and any nonpermeable surface is neglected. Using Eq. 6, the distribution of a steady GWL was simulated subject to a certain degree of SLR.

Distributions of the permeable soil layer, impermeable rock surface, and ground level in the objective region were estimated using the spatial interpolation method with a geographical information system (GIS). The coefficient of permeability was calculated using a linearly weighted combination of all soil layers up to the impermeable soil surface in each location. The weighting parameter was determined as the ratio of the soil layer thickness to the depth of the impermeable rock surface. The coefficient of soil permeability was estimated by reference to representative values of soils 
in Japan. Boundary conditions around the analyzed area were determined taking into account that not only the sea level, but also the river level, was affected by SLR.

Groundwater simulations before and after $0.8 \mathrm{~m}$ SLR were performed using the numerical method described above. Distributions of GWL rise subject to $0.8 \mathrm{~m}$ SLR are represented in Fig. 8. GWL rise on reclaimed islands is regarded as the same value as SLR because the sea surrounds the islands. The rise in GWL is close to $0.8 \mathrm{~m}$ when approaching the coastline. However, the GWL rise is not always large near the coastline. The figure shows a larger value of GWL rise along the Tsurumi River. GWL rise is different on each side of the river. For that reason and others, it is necessary for investigations of groundwater-related geodisasters to evaluate the distribution of GWL considering regional ground characteristics.

Instability of foundations and superstructures caused by rising groundwater levels

A rising GWL influences the ground, substructures, and superstructures. The illustrative sketch in Fig. 9 allows visualization of some issues arising from elevated GWL.

\section{Decreased bearing capacity and increased settlement}

The following events might take place when GWL rises and finally reaches the bottom of foundations: (1) ground-soil swelling because of adsorption, (2) decreased bearing capacity, and (3) increased

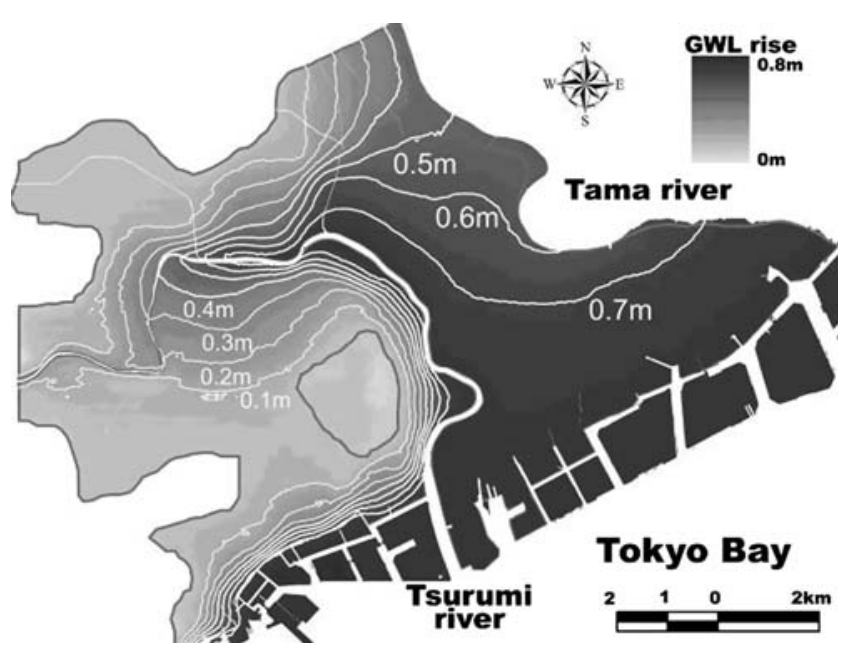

Fig. 8 Rise in groundwater level (GWL) subjected to $0.8 \mathrm{~m}$ sealevel rise (SLR) (Yokohama and Kawasaki, Kanagawa, Japan; Murakami et al. 2005) settlement resulting from increased shear stress levels in the ground. Methods for evaluating the decreased bearing capacity and increased settlement were described in a previous paper (Yasuhara et al. 2003). Following the previously described methodologies, a family of computed results describing both the bearing capacity decrease and settlement increase is shown in Fig. 10. Forecasting settlement and rebound of foundations due to the rise in GWL requires the determination of soil parameters and calculation of the overconsolidation ratio (OCR) of the ground depending on the GWL's position. For example, a footing with L/B ( $L$ assumed length of foundations $)=100$, as shown in Fig. 9, is assumed to be built on clay, unit weight $14.0 \mathrm{kN} / \mathrm{m}^{3}$, bearing capacity $q_{\mathrm{f}, \mathrm{NC}}=145 \mathrm{kPa}$, Poisson's ratio $v=0.34, \Lambda_{\mathrm{o}}=0.596$, and $C=0.26$, which correspond to typical values for a clay soil. Results from the numerical computation using the proposed methods are illustrated in Fig. 10 in the form of immediate settlement, $\Delta S_{\mathrm{i}, \mathrm{NC}}$, plotted against the rise in GWL; $\Delta h_{\mathrm{w}}$, as a parameter of stiffness index; and $E / s_{\mathrm{u}}$, where $E$ represents Young's modulus and $s_{\mathrm{u}}$ is the undrained strength of the clay. Figure 10 indicates that:

1. Immediate settlement increases with rising GWL normalized by the width of the foundation; $h_{\mathrm{w}} / \mathrm{B}$. The results from the increase in settlements are greatest when $\Delta h_{\mathrm{w}} / B$ equals unity. In that case, $\Delta h_{\mathrm{w}}$ extends above the base of the foundation.

2. Immediate settlement decreases with increased normalized depth of foundation.

3. Immediate settlement increases with decreasing $E / s_{\mathrm{u}}$.

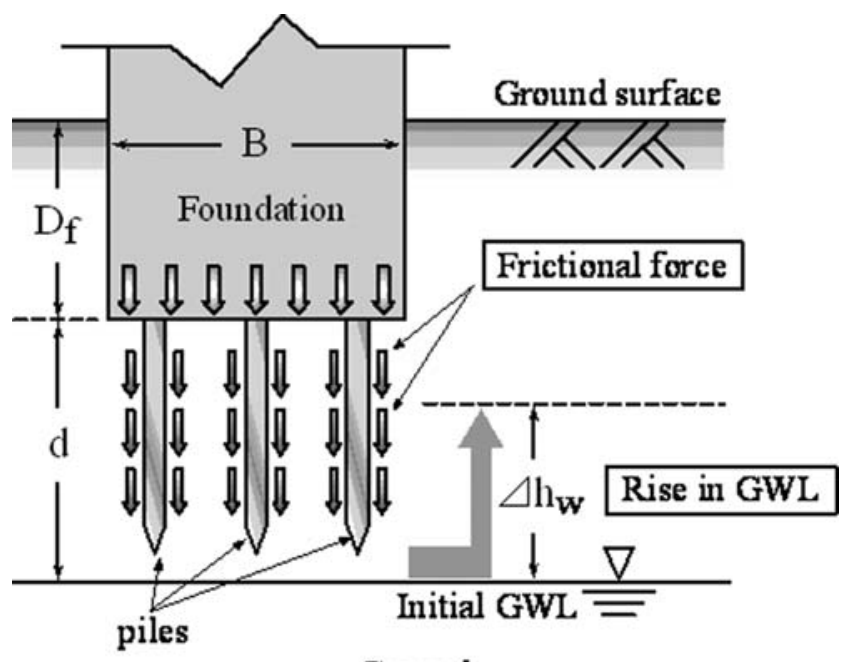

\section{Ground}

Fig. 9 Model ground with foundations undergoing rise in groundwater level (GWL) 
(a)

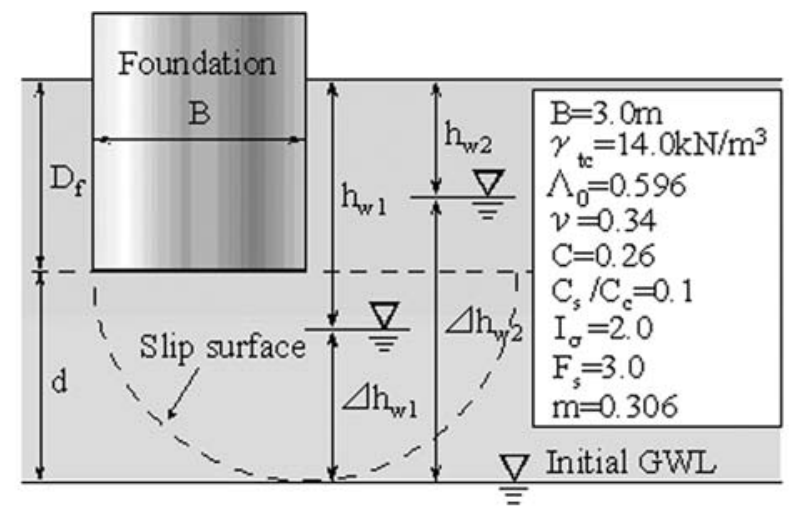

(b)
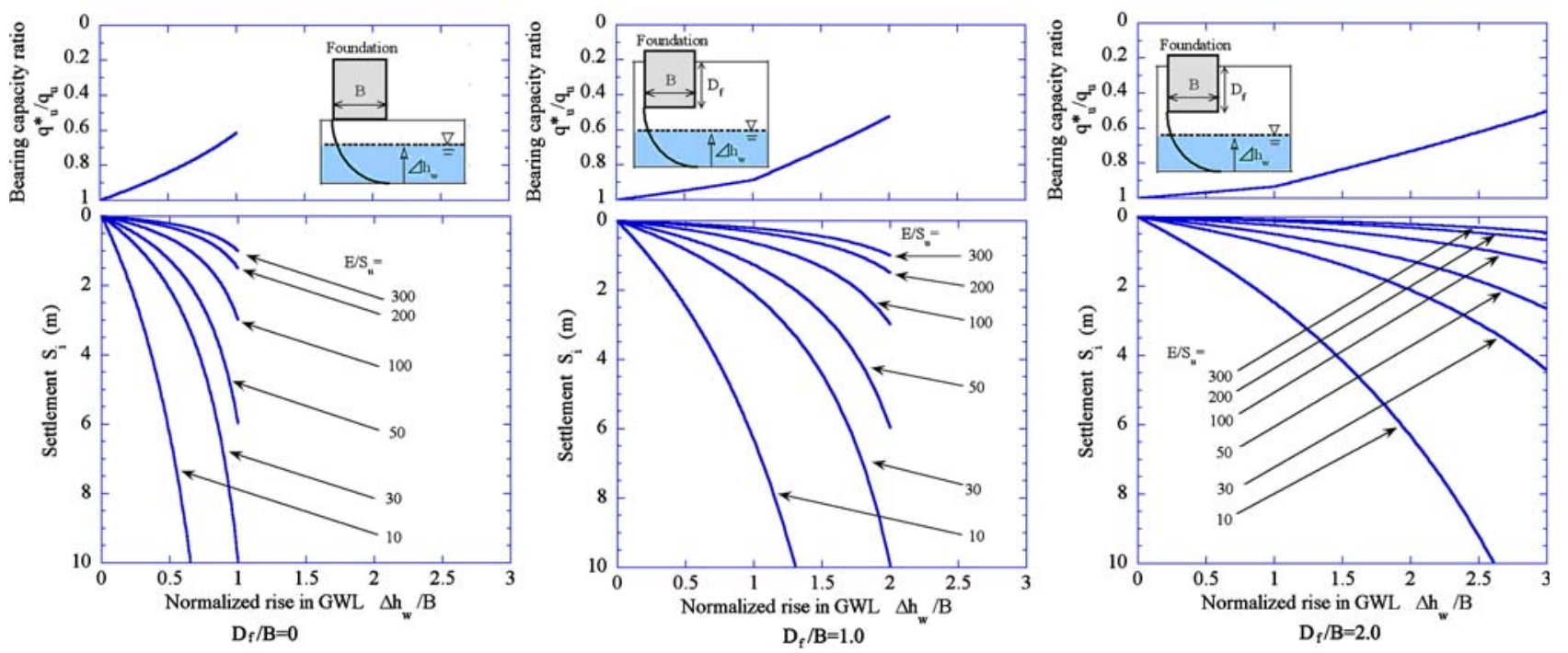

Fig. 10 Example of calculated results for instability of foundations undergoing rise in groundwater level (GWL)

\section{Floating of superstructures}

Deep foundations usually increase stability, but it should be noted that superstructures might be subjected to excessive uplift, leading to floating of structures. In more severe cases, cracks in the lower faces of foundations will eventually engender water leakage into the structure. Consequently, some countermeasures should be taken to resist floating. This will be explained later in greater detail.

\section{Increase in liquefaction potential caused by the rising GWL}

This study uses a procedure proposed by The Japanese Highway Bridge Code (JHBC; "Dorokyo-shihousho" in Japanese) originally produced by the Ministry of Construction (now the Ministry of Land, Infrastructure and Transportation) in 1990 and later in 1996 after the Hyogo-ken Nanbu earthquake in 1995. The revised version has been adopted for determining liquefaction potential. The procedure is based on the liquefaction resistance factor, $F_{L}$, given as

$F_{L}=\frac{R}{L}$

where $R$ represents the shear stress ratio expressing the liquefaction resistance and $L$ is the shear stress ratio triggered by earthquakes.

\section{Case histories}

Land subsidence and sea-level rise

\section{Osaka City}

Osaka mostly comprises alluvial deposits, forming a wide lowland. To date, the city has been devastated by storm surges from three major typhoons: Muroto on 21 


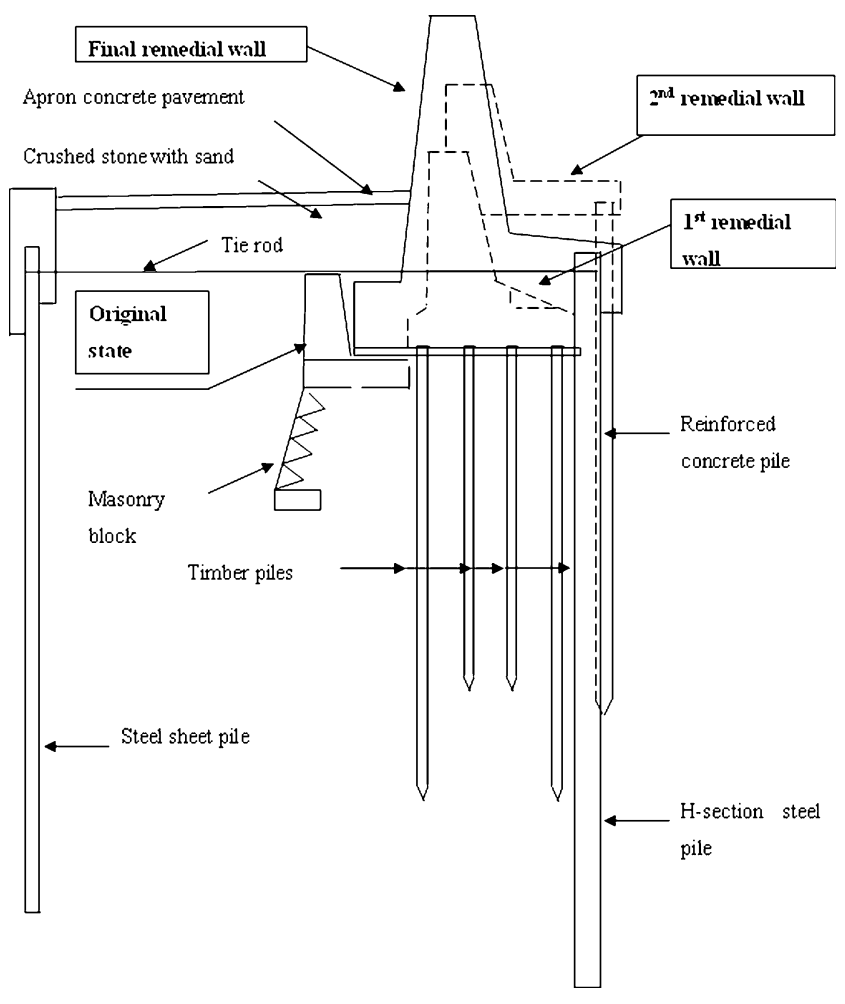

Fig. 11 Sketch for an example of remedial tide embankment in Osaka, Japan (Okumura 1993)

September 1934, Jane on 3 September 1950, and Muroto November 2 on 16 September 1961. The devastating damage was accelerated by land subsidence (Okumura 1993). However, the city still forms a large lowland area, although this has decreased year by year. Generally speaking, consolidation settlement induced by abstraction of groundwater is irreversible and hardly recovers, even if the GWL returns. Countermeasures are needed for large typhoons, such as the Isewan Typhoon in 1959. Typical countermeasures adopted in Osaka are raising tide gates and tide embankments. A typical example is shown in Fig. 11. In this case, construction of revetments on embankments has been repeated according to the amount of land subsidence. Therefore, if Osaka should suffer SLR, then this countermeasure would be adopted. In addition, municipal authorities have prepared sea walls in the reclaimed land in Nanko in Osaka, and new techniques are anticipated to renovate old embankments and tide gates using technologies such as geosynthetic reinforced earth structures.

\section{Bangkok, Thailand}

Prediction for global SLR over the coming century has serious implications for low-lying regions on the northern end of the Bangkok bight (Somboon and Thiramongkol 1993). The most pressing challenge for Bangkok now is related to the excessive exploitation of groundwater, which has engendered extensive land subsidence and groundwater contamination. An SLR will exacerbate these problems in the Bangkok area, affecting residential zones, surface water and groundwater pollution, river and sea flooding, wastewater drainage and treatment, drainage to agricultural lands, and industrial and commercial activities.

The geomorphology of the Bangkok metropolis has been largely ignored in the planning and development of the city. Decision makers require some basis for establishing such principles when faced with the question of selecting suitable areas for development, especially if parts of the municipalities must confront either natural or human-activity-induced hazards. Of the technical constraints to Bangkok's urban development, the most serious problems are related to excessive exploitation of groundwater, leading to extensive land subsidence year by year, even though it has remained stable for 5 years. Bangkok must also confront the prospect of SLR of about $1 \mathrm{~m}$ over the next 100 years (IPCC 1996, 2001). That increase will greatly exacerbate the flooding problem, especially during severe tropical storms, which are expected to become more frequent as atmospheric temperatures increase. The environmental impacts of SLR will create problems for urban growth, such as pollution of surface water, increasing difficulties of wastewater drainage and treatment, and maintenance of good water quality. Because increasing water demand will accompany Bangkok's increasing population, the SLR is expected to become an even more serious problem.

Bangkok can respond to the predicted rise in sea level by either trying to defend its land area or to move present activities and development to places that are more suitable. Dykes, sea walls, river levees, artificial filling, and other engineering works can protect the city, but economic and environmental impacts might render such a strategy unacceptable. In addition, moving present activities will have a serious economic and social effect on the city. It is therefore expected that city planners will be compelled to do more longterm studies to solve these problems.

In view of the above, groundwater abstraction has already been regulated over the past 10 years. The success of that regulation has reduced land subsidence, leading to the present stable situation. Notwithstanding, Thailand's leaders should give special attention to future influences of SLR in lowlands that have already suffered land subsidence, because this kind of settlement can never recover. 
Liquefaction potential near the river and coast in Kanagawa, Japan

As described previously, the GWL has recovered and risen in Japan because of regulation of groundwater abstraction in urban areas (Yasuhara et al. 2004) (see Fig. 7). Consequently, that rising GWL sometimes triggers damage to or instability of infrastructures such as railway facilities. In addition, there is concern that the SLR caused by global warming might raise the GWL (see Fig. 6). Concomitant with this kind of possible damage or instability, it is also expected that the liquefaction potential of sand deposits will increase as a result of the rising GWL. The geographical information system is a very powerful tool for decision-making strategies for mitigating and preventing natural hazards of this kind in urban areas, particularly geotechnical-related natural hazards such as settlement and deformation of structures and ground liquefaction. A GIS can visually portray current situations and sometimes present future situations for a wide objective area in which this kind of damage might occur. The most important issues for limiting damage are (1) to gather, integrate, and process information that is presently available from geographical, geomorphologic, geological, and geotechnical investigations; and (2) to create new information at locations without any investigations using statistical techniques for interpolation and extrapolation from the current data. The authors' current research efforts are intended to produce a GIS-based hazard map for liquefaction, particularly regarding the increased possibility of liquefaction exacerbated by rising GWL for two areas in the Kanto region around Tokyo. Knowledge from geostatistics is essential for extrapolation and interpolation of information on GWL, depth of liquefiable soils, and the properties required for predicting the possibility of liquefaction. Thereby, it fosters increased reliability of the hazard map. Locations that are sensitive to rising GWL are understood easily in terms of the GIS-based hazard map, which also shows where the liquefaction potential has increased because of rising GWL in the objective area. This benefit serves to confirm GIS as a powerful tool for determining countermeasures and strategies for preventing and mitigating liquefaction and liquefaction-induced instability and damage of infrastructure in the objective area.

\section{A hazard map for liquefaction using GIS}

Characterization of GIS and its utilization In order to produce a hazard map using previously published data from the literature and reports, we first intend to pro- duce a database comprising boring locations and geotechnical information. Then we will estimate the liquefaction potential of each location in the objective area. Subsequently, planar development will be performed using point information obtained through site investigation. Thus, we will create an electronic database map using GIS, which is most suitable for the sequential work described above. This study employs GIS for an updated-type hazard liquefaction map. Using it, necessary geoinformation can be input and renewed from time to time to alert all users to the most recent hazard probability situation engendered by earthquake-induced liquefaction.

\section{Producing the electronic hazard database map}

Geoinformation collection Yokohama City in Kanagawa Prefecture was selected as the objective area for investigation of liquefaction hazards. Natural banks and back wetlands extend along the river bottom of the Tsurumi River in Yokohama City. In particular, sandbars and sandbanks are easily liquefied because they constitute sandy deposits. Outlines of the geographical and geomorphologic situations on the Tsurumi River are shown in Fig. 12, along with boring and sampling locations.

Interpolation of data Interpolation is necessary because data necessary for predicting the liquefaction potential using Eq. 7 are not always available at every boring location. Data required for estimating the liquefaction potential $F_{L}$ given by JHBC (Japan Highway Bridge Code), was obtained from approximate values given in the Road Bridges Specification for Toride City and average values for Yokohama City obtained from site investigations. Regarding the GWL, estimation

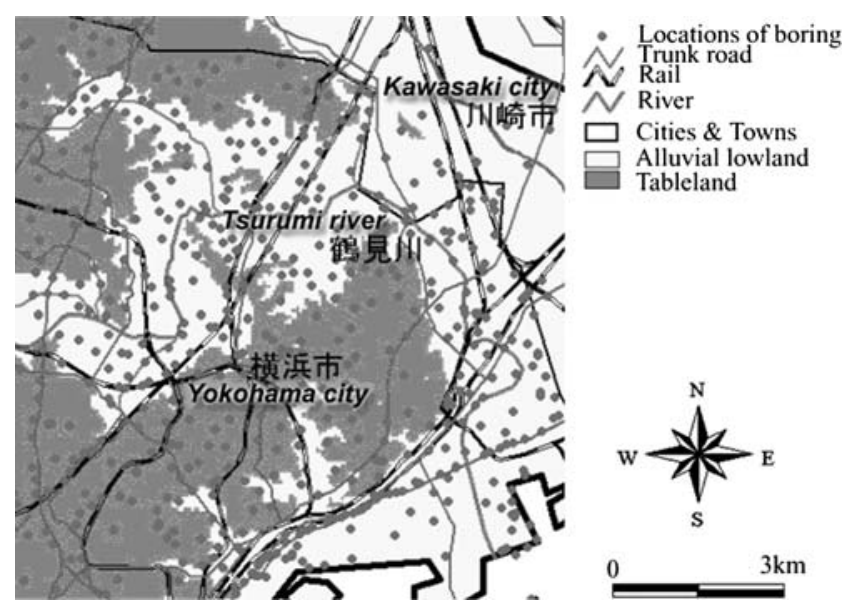

Fig. 12 Locations of boring data in Yokohama City 
was done using the Kriging method, which has conventionally been adopted in the field of geostatistics.

Using GIS for preparation of an electronic hazard map for liquefaction Making use of the interpolated geoinformation, we estimated the liquefaction potential for Toride and Yokohama Cities using the old and new methods proposed in JHBC (Japan Road Association 1990, 1996), considering the effects of rising GWL. A liquefaction hazard map was produced based on these results. This work demonstrates the planar distribution of the liquefaction potential, $P_{L}$ value, by applying the Kriging interpolation method to boring locations. The $P_{L}$ is given as

$P_{L}=\int_{0}^{20} F w(z) \mathrm{d} z=\sum_{i=1}^{20} F w(z) \Delta z$

where

$$
\left.\begin{array}{l}
F=1-F_{L}\left(F_{L}<1.0\right) \\
F=0\left(F_{L}>1.0\right)
\end{array}\right\}
$$

$w(z)=10.0-0.5 z$

and $z$ is the depth. The liquefaction potential given by Eq. 8 gives feasibility throughout the soil deposit at the objective location, while the liquefaction index, $F_{L}$ is given by Eq. 7 .

\section{Liquefaction hazard map for the rise in GWL}

Because of regulations aimed at groundwater abstraction for reducing land subsidence in large cities in Japan, such as Tokyo and Osaka, the GWL has been rising. This rising GWL has engendered instability of infrastructures and their foundations (e.g., Yasuhara et al. 2003). In addition, it has been inferred that the rising sea level caused by global warming will further raise the GWL. This raised GWL will raise the liquefaction probability in sandy soil deposits. As an example, liquefaction potentials were calculated for the area along the Tsurumi River in Yokohama, Japan, for which geographical information is given in Fig. 12. The results are presented as a hazard map using GIS assuming increases of GWL of $0.5,1.0$, and $1.5 \mathrm{~m}$, respectively. Figure $13 \mathrm{a}-\mathrm{c}$ depicts hazard maps in which the distribution of calculated $\mathrm{P}_{\mathrm{L}}$ values, assuming type II earthquake motion (type I and II earthquake motions corresponding, respectively, to the Great Kanto earthquake disaster in 1923 and the Great Hanshin earthquake in 1995) are shown corre- (a)

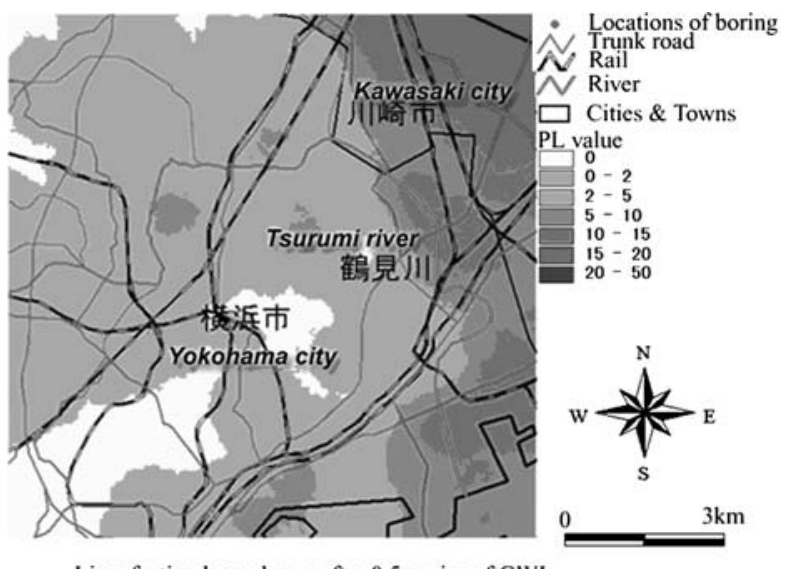

Liquefaction hazard map after $0.5 \mathrm{~m}$ rise of GWL

(b)

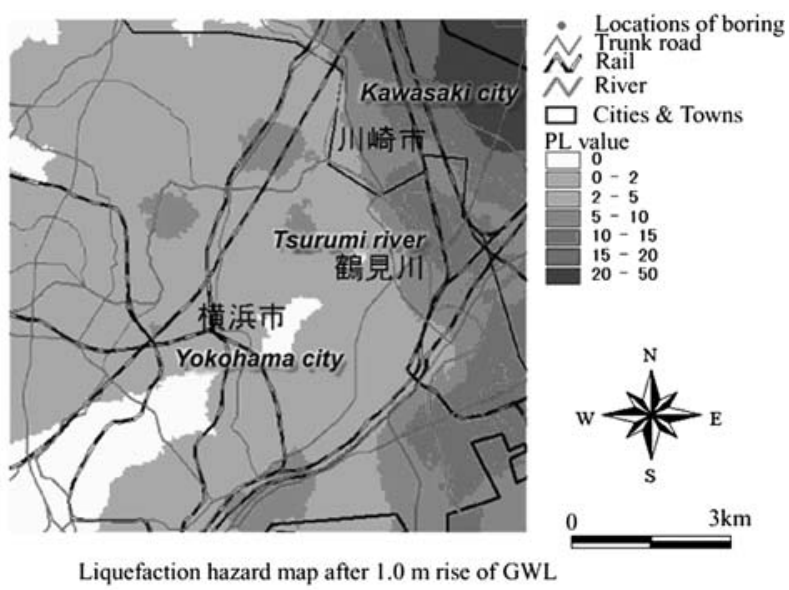

(c)

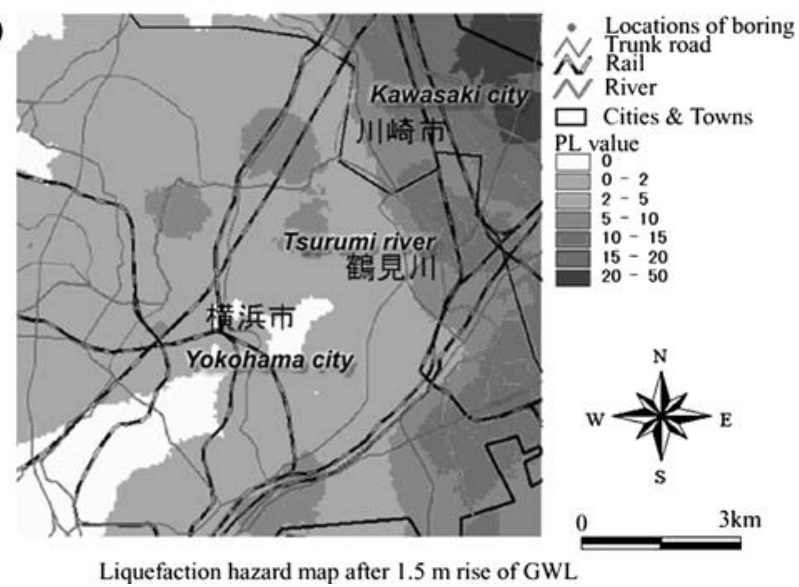

Fig. 13 Influence on groundwater-level (GWL) rise to liquefaction hazard map using the new standard (1996 type II), a liquefaction hazard map after $0.5-\mathrm{m}$ rise of GWL, b liquefaction hazard map after 1.0-m rise of GWL, and $\mathbf{c}$ liquefaction hazard map after $1.5-\mathrm{m}$ rise of GWL

sponding, respectively, to rising GWLs of $0.5,1.0$, and $1.5 \mathrm{~m}$. Comparison of Fig. 13a-c shows the liquefaction potential increasing and its area extending with increasingly raised GWL. Particularly noteworthy is the fact that an area with low probability of liquefaction 
before the rise in GWL was converted into one with a high probability. The probability of liquefaction increases with increasing thickness of saturated liquefiable soil layers and decreasing effective overburden pressure of soils. This conversion apparently occurs because regions where the probability of liquefaction changes are influenced by such factors as a result of the rise in GWL.

\section{Response and adaptation strategies against infrastructure instability triggered by global warming}

\section{Concept of strategy}

Events triggered by SLR because of global warming are classifiable into the following: (1) chemical influence of the intrusion of salt water into groundwater, and (2) physical influences of invasion of salt water into the groundwater, mainly leading to a rise in GWL. Of those events, the chemical influences on earth structures have not been clarified and therefore remain for further investigation and study. On the other hand, the physical influences include (1) direct damage from rising GWL and (2) indirect dual damage caused by a combination of an earthquake with raised GWL. We should create innovative techniques by combining traditional and conventional methodologies to cope with problems that have already emerged and which will threaten global human society. Table 2 depicts a conceptual procedure that might yield promising techniques.

Menu of response and adaptation

Countermeasures against ground damage caused by rising GWL are shown in Table 3 and can be described as follows:

1. Land subsidence: regulation of groundwater abstraction is the most popular and effective measure for reducing land subsidence. It has aided most areas suffering land subsidence, such as Tokyo, Bangkok, and Hanoi. However, land subsidence never recovers and subsequently produces lowland conditions. Therefore, such measures as construction of breakwaters or seawalls are required as the land subsidence area becomes more vulnerable.

2. Liquefaction: the possibility of liquefaction in sand deposits increases due to raised GWL. Therefore, installation of drainage facilities is a countermeasure in urban areas. Alternatively, the use of excessive surface water from heavy rainfall and use of groundwater in heat islands in urban areas such as in Tokyo are also effective measures for reducing the instability of sand due to lowering of the GWL.
Table 2 Response and adaptation strategies against damage due to sea-level rise (SLR)

\begin{tabular}{cll}
\hline & Traditional or & Innovative measures \\
& conventional measures & \\
\hline Developing & Revetment & Gabion \\
Grointries & Concrete wall \\
& Planting mangrove & Ground improvement \\
& Natural geosynthetics & Geosynthetics \\
such as jute & \\
Concrete wall & Against single hazard \\
& Installation of piles \\
& Lowering groundwater level (GWL) \\
& Upgrading embankment (e.g., superdykes) \\
& Ground improvement \\
& Improvement of density \\
& Adding drainage system \\
& Adding chemical materials \\
& Utilization of carbon oxide \\
& Ground reinforcement \\
& Geosynthetics \\
& Geosynthetics with cement or quicklime \\
& Against dual hazards \\
& Lowering GWL \\
& Piles for mitigation of liquefaction \\
& Cement treatment \\
& Gravel drain, particularly using \\
& recycled materials \\
&
\end{tabular}


Table 3 Issues in infrastructures triggered by rise in groundwater level (GWL) and their countermeasures

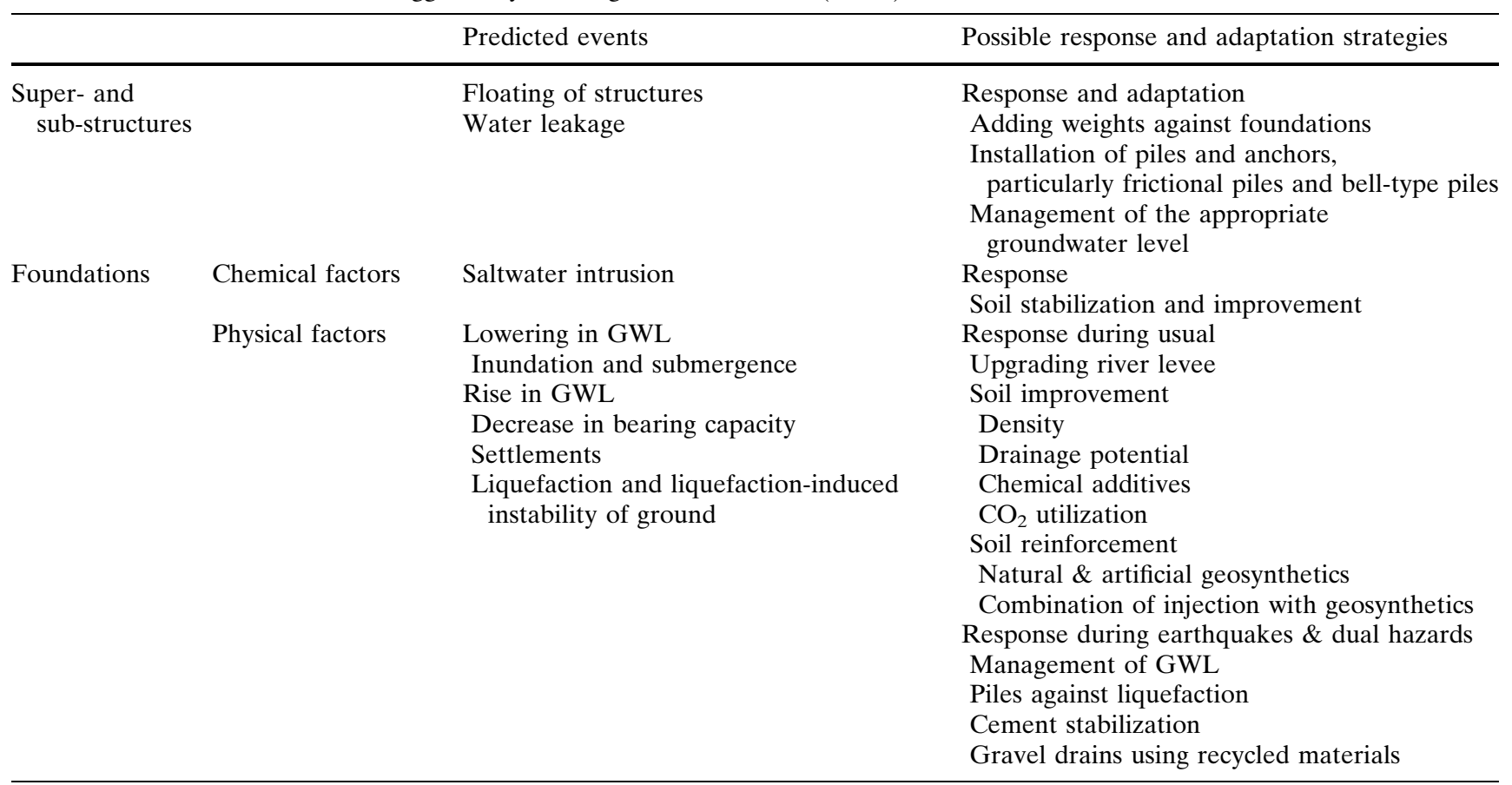

3. Floating of structures: Installation of piles and anchor piles was adopted as a preventive measure against possible floating of station buildings at Kodaira, Ueno, and Tokyo caused by uplift forces from abruptly rising GWL. Abstraction of groundwater also prevents floating of underground structures and superstructures. However, this might cause land subsidence. Therefore, we should find optimal GWL for preventing both floating of structures and land subsidence through careful monitoring of GWL.

\section{Conclusions}

1. After an overview of possible instability of infrastructure caused by global warming, methodologies are proposed for mitigating the increasing probability of instability triggered by variations of GWL, which are particularly serious in coastal regions because of SLR as a result of global warming.

2. An attempt has been made to construct an electronic hazard map using GIS, showing probable areas of liquefaction. The map provides planar visualization of the objective area. This hazard map can be continually updated with new data. In this sense, the hazard map using GIS can be called a "real-time electronic map." Thus, GIS is a powerful tool for maintaining local and global sustainability.

3. When land subsidence becomes severe in coastal regions, the effects of SLR increase. The probability of liquefaction attributable to earthquakes increases if GWL rises along with SLR. Case histories illustrate these possibilities as an important influence of global warming on infrastructural integrity. Therefore, it is important to monitor GWL as much as possible.

4. From the distribution of liquefiable sand deposits and their thickness, areas with low liquefaction probability have been reevaluated using GIS as high probability after a rise in GWL. In particular, in regions of deeper sand deposits, the increase in liquefied layers is more marked and the liquefaction potential has increased with rising GWL. GIS offers the advantage of illustrating the extended area of liquefaction potential because of the rise in GWL.

5. Finally, possible countermeasures and adaptation strategies for mitigating instability and damage to infrastructure and the ground are described for each case in specific regions. In particular, it is emphasized that the use of geosynthetics is favorable, particularly for protecting coastal areas, which are likely to be influenced by SLR resulting from climate change. 
6. Special attention should be given to adaptation strategies in lowland and coastal areas that have suffered from land subsidence.

Acknowledgments The current study was supported financially by grants-in-aid from the Ministry of Education, Culture, Sports, Science and Technology (the project representative is Professor Nobuo Mimura of Ibaraki University). This work was also supported by the Global Environment Research Fund under the research subject titled "Comprehensive assessment of climate change impacts to determine the dangerous level of global warming and to determine appropriate stabilization target of atmospheric GHG concentration".

\section{References}

IPCC (1996) Climate change 1995, impacts, adaptations and mitigation of climate changes. Cambridge University Press, Cambridge, pp 365-398

IPCC WGI (2001) Technical summary, climate change 2001: the scientific basis, contribution of working group i to the third assessment report of the intergovernmental panel on climate change. Cambridge University Press, Cambridge, p 83

Japan Road Association (1990) The Japanese highway bridge code v. Earthquake-resistance design (in Japanese)

Japan Road Association (1996) The Japanese highway bridge code v. Earthquake-resistance design (in Japanese)

Kusumi K, Matano (2005) Protection of subway station against recovery of groundwater table (in Japanese). Tunn Undergr 36(8):33-40

Murakami S, Yasuhara K, Mochizuki N (2002) An observational prediction of land subsidence for a GIS-aided monitoring system of groundwater level. Lowl Technol Int 4(1):46-61
Murakami S, Yasuhara K, Suzuki N, Ni Wei, Komine H (2005) Vulnerability assessment to liquefaction hazard induced by rising sea-levels due to global warming. Proceedings International Conference on Geotechnical Engineering for Disaster Mitigation and Rehabilitation vol 1 pp 571-576

Okumura, R (1993) Land subsidence and countermeasures against storm surge in the city of Osaka, Japan. In: IPCC Eastern hemisphere workshop on vulnerability assessment to sea level rise and coastal zone management, Tsukuba, pp 259-267

Recio-Molina J, Yasuhara K (2005) Stability of modified geotextile wrap around revetments (GWR) for coastal protection. Geosynth Int J 12(5):260-268

Saathoff F, Zitscher F (2001) Geokunststoffe in der Geotechnik und im Wasserbau (geosynthetics in the geotechnics and in hydraulic applications), pocket book from Naue Fasetechnik and Bauberatung Geokunstoffe, Germany, pp 23-40

Somboon JRP, Thiramongkol (1993) Effect of sea level rise on the north coast of the bight of Bangkok, Thailand. Malays J Trop Geogr 24(1/2):3-12

Yasuhara K, Adachi M (1994) Influences of sea level rise due to global warming on earth structures and foundations (in Japanese). J Jpn Geotechn Soc (Tsuchi-to-Kiso) 429(437):51-54

Yasuhara K, Murakami S, Mitsuyama S (2003) Instability of foundations undergoing rise in groundwater level. In: Proceedings of international symposium on groundwater problems related to geo-environment (IS-Okayama), vol 1 pp 205-210

Yasuhara K, Murakami S, Fukuda T (2004) GIS application for prediction of liquefaction potential caused by rising groundwater level. In: Proceedings of international conference on engineering practice and performance of soft deposits. IS Osaka, pp 433-438 